\title{
Cultural Margins, Hybrid Scripts
}

\section{Bigraphism and Translation in Taiwanese Indigenous Writing}

\author{
Andrea Bachner \\ Cornell University \\ asb76@cornell.edu
}

\begin{abstract}
Since its emergence in the 1980 s, Taiwanese Indigenous writing has constituted a case of minor literature that mostly uses the culturally dominant language of Chinese, rather than indigenous languages, for literary creation. Framed conventionally as cultural traditions without writing in spite of the existence of Romanized script systems for Taiwan's indigenous languages, the literary expressions of Taiwan's first cultures face a situation of linguistic diglossia accompanied by that of bigraphism, one of profound inequality between two languages as well as between their script systems. This essay analyzes two recent texts by Taiwanese indigenous authors, Badai's Diguwan:Damalagaw during the Taisho Years (2007) and Rahic Talif's Turbidity (2006), for their textual strategies of linguistic and script mixing, in order to explore the complex politics of translation at Taiwan's cultural margin and beyond.
\end{abstract}

\section{Keywords}

indigenous writing - Taiwanese literature - script mixing - translation - Badai - Rahic Talif

\section{"Savage" Writing}

One of the anagrammatic poems in the 2007 collection Light/Slow (輕 / 慢) by Taiwanese poet Chen Li 陳黎, “Clan” (氏), addresses the question of Indigenous writing in particularly glaring terms. From the perspective of an Indigenous individual who reflects on and refutes the Han-centrism that casts him or her as savage, the poem sets up a binary between the Indigenous margin and the Chinese center. The disadvantaged position of Indigenous cultures that the 
poem contests is not only expressed in terms of high and low or human and inhuman. It resides most importantly in access to writing - the hallmark of civilization for Chinese (as well as other) cultures. Deprived of a name and of written language- “I have no name, I have no writing” (我沒有名字, 沒有 文字) — the lyrical I still resists the center that establishes its exclusive vision of civilization, even “with broken hands, without a brush" (斷手缺筆) (59-6o). And yet, in Chen Li's poem, the apparent binary between Chinese culture, characterized by writing, and Indigenous culture, characterized by the lack of writing, is bridged by a poetic sleight of hand. Even though the voice of the poem does not have a personal name, s/he claims another, more important name, that of his or her clan: "My face is my clan name/From the tattoo on my lower jaw/I derive my name, see clearly-/Di” (我的臉就是我的姓氏/我在我 的下顎刺青/自我命名, 看清楚一/ 氏). Through an anagrammatic play with the Chinese characters “氏” ("clan") and “氏” "“i”"), the text gives not only voice, but also, in a supplemental turn, writing to the subaltern subject thematized in the poem. In Chen Li's "Clan," the Di ethnicity are given a name through the graphic materialization of the imaginary of tattooing: a spot or line added to the lower jaw, i.e. to the character for clan, “氏," that results in “氏” and constitutes the solution of this anagrammatic riddle poem. By crafting a link between Chinese writing and tattooing, Chen Li breaches the chasm between writing and non-writing, between civilization and its (alleged) others. By the same token, however, he brings Chinese cultures closer to Indigenous cultures by equating writing and tattooing, albeit imaginarily. ${ }^{1}$

The Di of Chen Li's poem constitute one of the "Five Savages" of ancient China. And yet, the poet's sustained interest in Taiwanese Indigenous cultures suggests that the Di of "Clan" speak to the tension between Chinese cultures and its Indigenous others in general, and thus also to the fraught relationship between Taiwan's Indigenous cultures and its Sinophone settler culture. Chen Li's poetic connection between tattoos and Chinese characters is profoundly ambivalent. Although it critically relativizes the difference between cultures with writing and those deemed without writing, it can also be read as perpetuating cultural inequalities by way of a problematic equation. ${ }^{2}$ On the one hand, the Indigenous practice of tattooing, or so it seems, accrues value only through

1 Chen Li might be alluding here to one of the hypotheses for the origins of the character for writing (wen) that embodies the cherished tradition of Chinese civilization: pattern and tattoo, see James J.Y. Liu's discussion and refutation of this theory in Chinese Theories of Literature (7 and footnote on 142).

2 In Of Grammatology, Jacques Derrida famously challenged the anthropological bias toward cultures without writing by proposing a more capacious definition of writing. 
its similarity with Chinese writing - almost the same but not quite. On the other, through this imaginary link, Taiwanese culture can claim, as Chen Li formulates it in the 1995 postface to his collection The Edge of the Island (島嶼邊 緣), "a kind of vitality that springs from a ceaseless hybridization and inclusion" (192). Chen Li's "Clan" thus points to the fraught, yet potentially productive friction between Chinese script culture and Indigenous cultures traditionally reliant on orature. For my purpose, "Clan" addresses the tension inherent in the emergence of Taiwanese Indigenous writing over the past decades, not only between Indigenous languages and the dominant Sinophones (standard Mandarin and Taiwanese), but also between two different scripts, Chinese characters and the Romanized writing systems developed for Taiwan's Indigenous languages.

The current climate in which Indigenous cultures have emerged as an important symbolic component of Taiwanese identity marks only the development of the past few decades and comes in the wake of several hundred years during which Taiwanese aborigines - often labeled as uncivilized savages-were deemed obstacles to the interests of colonization and modernity at worst, or treated with indifference or neglect at best. From the influx of Han Chinese in the seventeenth century, throughout Japanese colonial rule (1895-1945), the period of Chinese Nationalist control of Taiwan after 1945, and up to the 1980s, Taiwan's Indigenous population, part of the Austronesian peoples, who had lived on the island for about eight thousand years, were deemed expendable, facing repression, decimation, as well as loss of land and cultural traditions. Taiwan's turn toward a strategically hybrid self-understanding in the face of the PRC's hold on an ideal of Chineseness also found an imaginary place for its Indigenous populations - in public and political discourse as well as in intellectual and artistic practices.

The recent interest in Taiwan's Indigenous cultures has been accompanied by improvements in the material and cultural lives of Indigenous communities, such as increased opportunities for learning their mother tongues in schools, TV programs in Indigenous languages, scholarly interest in and forums for preserving Indigenous cultures, or literary prizes and access to publishing venues for Indigenous literature. And yet, in a climate of cultural, political, and economic inequality, Indigenous languages are only gradually emerging from a situation of suppression at worst and diglossia at best. Given the predominance of Chinese script culture in Taiwan and the relatively recent creation of standardized writing systems for Indigenous languages, they still tend to be confined to local or domestic use, whereas standard Chinese and Taiwanese garner more linguistic prestige as official languages and vehicles of education and culture. This effectively extends a diglossic situation to one of bigraphism, a 
situation of unequal bilingualism that involves two different scripts- the elite vehicle of Chinese characters against the secondary, newly fledged Romanized writing systems of Indigenous languages. ${ }^{3}$

This has a profound impact on the conditions for Indigenous literary production. In spite of the advances in preserving and promoting Taiwan's Indigenous languages and cultures, only a small fraction of Taiwan's Indigenous literature (原住民文學), which has experienced an unprecedented boom since the late 1980 , is written in Indigenous languages. Its vast majority, although crafted by members of Indigenous ethnicities and often by definition circumscribed to "Indigenous" topics, is written in Chinese. Because of the long history of colonial assimilation and the suppression of Indigenous languages, Chinese has become the "native" language of many Indigenous individuals, while communities of fully functional users of Indigenous languages are in decline. The linguistic politics of Taiwanese Indigenous writing are particularly complicated because of the strong contrast between Chinese writing with its long script history and the status of Indigenous traditions deemed to be cultures without writing. In fact, with their rich traditions of storytelling, songs, enchantments, and rituals, Indigenous cultures have traditionally relied on orature rather than on written traditions, and their relatively recent history of writing has often coincided with a history of disenfranchisement. Following Taiwan's multi-layered colonial history, Indigenous expressions were being transformed from oral performance into written documents by way of different transcription systemsranging from names to entire texts and finally, in the last decades, to the development of official, systematic Romanized transcription systems for each of the extant Indigenous languages of Taiwan. ${ }^{4}$ The choice of Chinese as literary medium for Taiwanese Indigenous literature responds to the unequal distribution of linguistic power and educational pressures, as well as to questions of cultural circulation: since the extant Indigenous languages of Taiwan (and sometimes even their variants) are not mutually intelligible and the different Indigenous cultures constitute only about two percent of Taiwan's population, writing in an Indigenous language can only reach an extremely small readership.

3 I am not using the term "digraphia" for this phenomenon, even though it would make for an elegant parallel to diglossia that might carry some notion of the unequal prestige between two different scripts (associated with two different languages). However, "digraphia" is used to indicate a situation in which one and the same language is written in two different scripts (either diachronically or synchronically).

4 For an overview of a history of different transcription systems for Taiwan's Indigenous languages, see Zeitoun and Hua 171-4. 
But even as the use of the more widely read medium of Chinese for the minor literatures of Taiwan's Indigenous cultures might be pragmatically warranted, Indigenous writing in Chinese might never amount to more than an extremely marginal part of Taiwanese and an even more marginal part of Chinese literature either, as Atayal 泰雅 writer Walis Nokan瓦歷斯·諾幹 argues (Lü 36). In contrast, for Puyuma 卑南 writer and critic Sun Dachuan 孫大川, indigenous writing needs to escape the "trap of essentializing the mother tongue" (23), but the questionable treatment of language as mere instrument of communication involves reifying other increasingly problematic categories, from ethnicity to cultural knowledge or an Indigenous "mindset." After all, Sun also calls for Indigenous writing to inflect and reshape its Chinese medium, a concern that resonates with theoretical reflections on minor literatures in major languages, as well as with an interest in Sinophone articulations that pit the hybridity of cultural expressions in Sinitic languages against Han- and sinocentric ideals (Huang 252). But while Indigenous writers undoubtedly continue to reshape the language of the colonizers, their own cultures continue to be affected by the hegemonic position of Chinese. Rather than reactivating binaries such as orality and writing, or resistance and assimilation, in what follows, I will consider two recent examples of Indigenous literature that espouse experimental ways of writing in Chinese without only writing in Chinese: the 2007 novel Diguwan: Damalagaw during the Taisho Years (笛鸛： 大巴六九部落之大正 年間) by Puyuma writer Badai 巴代 and the 2006 anthology Turbidity (Mangotaay/混濁) by Amis writer Rahic Talif 拉黑子. 達立夫. ${ }^{5}$ Both texts, as many other contemporary Taiwanese Indigenous texts, mix Indigenous languages and standard Chinese. What sets both texts apart and makes them particularly interesting for my purpose here is their use and scrutiny of textual registers that script modes of bilingualism and translation: anthropological texts for Badai and bilingual poetry editions for Rahic Talif. Consequently, the copresence of two languages and their two scripts produces texts that, even at

5 Both writers are fairly well known on the Taiwanese cultural scene-with the publication of their works in the Ryefield Indigenous Writers Series, one of the foremost publishers on Taiwan's literary scene, providing them with visibility — as well as vocal advocators for and teachers in their communities. Badai was born in 1962 to the Damalagaw tribe of the Puyuma in Taitung, southeast Taiwan. Before starting his writing career with his first novel Diguwan, which won the 2008 Taiwan Literature Award's Gold Prize, Badai worked in the Taiwanese military and earned an MA in Cultural Studies from the National University of Tainan with a thesis on shamanic rituals among the Puyuma. Rahic Talif was born in 1962 and moved back to his native Makuta'ay in eastern Taiwan in 1992. He is an Amis age-class leader, as well as a renowned sculptor. Turbidity (2006) is his first published anthology. 
a first glance, are fairly hybrid. And yet, the politics of translation adopted by Badai and Rahic Talif in their bilingual and bigraphic works that I will read closely in what follows also destabilize overly optimistic notions of the creative or resistant force of bilingual literature. In Bilingual Games, Doris Sommer strategically turns the "busy borders between languages," the precarity of living in or between two languages and cultures into an aesthetic asset, where code-switching, lateral moves between languages, and linguistic poaching constitute not only creative survival, but indeed drive aesthetic innovation (1-2). But not all bilingualisms are equal-and the bilingual aesthetics of Latino writers between English and Spanish, for instance-two languages of global importance, though not of equal prestige-look very different when one of the languages, for instance Badai's Puyuma, is used by a very small community of speakers. In contrast, Walter Mignolo's term bilanguaging, drawing on Latin American examples, especially the friction between the Spanish-language culture of the colonizers and the cultures of Indigenous populations, underlines that practices in the contact zones between different cultures and languages constitute a struggle rather than a game, "as a way of living in languages in a transnational world, as an educational and epistemological project [that] rests on the critique of reason, of disciplinary structures and cultures of scholarships complicit with national and imperial languages" (273).

What an analysis of Badai's and Rahic Talif's works shows is the unequal terrain of bilanguaging, one in which - given existing language politics, the unequal distribution of cultural and linguistic prestige, as well as existing literary (and non-literary) patterns, styles, genres, and transnational networks for the circulation of literary works profoundly shape and predetermine the choices of bilingual (and bigraphic) writers. By scrutinizing specific instances of Indigenous-Chinese cross-pollination we can start to put pressure on notions of hybridity and explore the complex politics of Indigenous writing and script mixing in Taiwan in ethnic, national, and global contexts instead.

\section{Bigraphic Boundaries}

Badai's novel Diguwan opts for a peculiar mixing of languages and scripts. The novel focuses on the Puyuma Damalagaw during the Japanese occupation in the early 1910 and their complex interactions with the colonizers, the local Chinese, and other Indigenous peoples. In preparation, its author, Badai, consulted Japanese documents and sought out oral accounts of the time among the Puyuma, realizing that both versions differ in almost every instance. The novel thus constitutes an attempt at countering the official narrative handed 
down in writing by the Japanese with a history produced from a Puyuma perspective, not merely one in which the Puyuma are subjects of history only by being subject to colonial rule and ideology. Such an alternative, unofficial history, a “野史," with its reference to "fieldwork (田野)-derived history" and as a kind of "wild (野) history" (13), straddles the realms of the written and the nonwritten by means of the literary genre of the historical novel. With its maps of Puyuma territory and its photographs of objects and rituals, Diguwan, while clearly labeled as a novel on its cover, ventures into the realms of historiography and anthropology. While this strategically stretches the boundaries of fiction, as a means of challenging the truth-status of historical documents as well as an alternative way of producing history, it also forces Badai's text to confront the ideological baggage of the discourses it subsumes, even as it critiques them.

The author's choice of narrative perspective speaks to its discursive and generic intertexts. In spite of the focus on an Indigenous perspective, stated clearly in the author's preface and adumbrated in using Diguwan, the name of a Puyuma shaman in the text, as title of the novel, ${ }^{6}$ the narrative is carried by an impersonal omniscient perspective that provides descriptions of characters, settings, and actions, often with explanations, but does not enter a character's perspective or thoughts. Since all dialogue is rendered as direct speech and is juxtaposed with an omniscient, though impersonal and neutral-sounding narration, the text creates the impression of an anthropological account that combines the anthropologist's explanatory framework as well as renditions of the voices of native informants. This narrative structure inflects some of the word choices in the novel. For instance, the seven Puyuma men who protagonize the opening scene are introduced as “七個漢子” ("seven men”). But while “漢子” can be translated as "man" in general, often with a connotation of strength and manliness, its use of the character “漢," or "Han(-Chinese)," gives the term an ethnic overtone that conflicts strangely with the novel's description of a group of manly Puyuma. In addition, the use of the term “頭人” ("headman”) which, as the author glosses, is an anthropological term for the leader of a tribal village (21, note 6), rather than that of a Puyuma term, is another-however small-instance of the sustained presence of an anthropological discourse with its advantages and pitfalls.

The gap between the narration and the characters' voices determines the language politics of the novel. While the novel's narrative is held entirely in

6 The fact that Badai opts to leave the title in Chinese, thus transcribing the Puyuma name Diguwan in Chinese as “笛鸛” already signals the importance of standard Chinese as the novel's main linguistic medium. 
standard Chinese, all dialogue appears first in the original language, namely in Puyuma (or in some cases in Taiwanese), followed immediately by a version in standard Chinese. On the one hand, this leads to a strongly visible presence of Puyuma text - in its Romanized transcription - in the novel, without sacrificing the text's legibility for readers of standard Chinese. In fact, Badai insists on the hybridity of his target audience as the novel not only attempts to give historical grounding to Puyuma culture, but also seeks to further intertribal dialogue and allow the general public to learn about Indigenous traditions (14). On the other, it also introduces a clear divide between the standard Chinese narration and Indigenous dialogue, compounding a difference in perspective with one of language and script. ${ }^{7}$ As the series editor Wuhe 舞鶴, a well-known Taiwanese writer whose work often engages topics of Taiwan's Indigenous peoples while he himself is not an Indigenous writer, underlines in a note (19, editor's addition to author's note 4), that the parts of the novel that are crafted in direct discourse were written in Puyuma (or for the dialogue of local Chinese in Taiwanese) first and then translated into standard Chinese. ${ }^{8}$ But whereas this underscores the authenticity of the Puyuma characters' voices, since standard Chinese is only the translation of the Puyuma original, the novel's direct discourse is still enclosed within a narrative framework written in standard Chinese. ${ }^{9}$

The intriguing choice of introducing direct dialogue in the mode of parallel translations is accompanied by a strange linguistic purity in the text on another level. The narrative text in standard Chinese is completely devoid of Puyuma terms, with the exception of names transcribed in Chinese characters and underlined to signal that these are proper names. The embargo on Puyuma words in the parts of the novel that are not in dialogue even applies to terms specific to Puyuma objects, such as typical weaponry or items of clothing. In

7 In the second volume of Badai's Damalagaw series, Mazizir (馬鐵路), published by Yelu in 2010, the Puyuma dialogue is further marginalized. Instead of the arrangement of text in Diguwan (front to back, top to bottom, left to right), in which the Puyuma text is followed by the Chinese translation in comparable font sizes, Mazizir returns to the format typical for literary texts published in Taiwan: back to front, right to left, top to bottom. The Puyuma original is pushed to the bottom of the page and printed in smaller font-almost like an afterthought of the Chinese translation.

8 Meanwhile, the direct discourse of Japanese or the indigenous Bunun 布儂 characters is rendered only in Chinese.

9 That the Chinese language is not merely an instrument of translation that erases its own linguistic specificity becomes clear in the "translations" of songs or incantations, since their rendition into Chinese produces Chinese versions with equal character lengths, at times even with rhymes, that are evidently carefully crafted with a view to Chinese poetic standards (see $\left.5^{2-3}, 177-8,301-2\right)$. 
the Chinese text, these appear usually as translations (rather than only transcriptions) into Chinese, while their Puyuma term is only provided in marginal notes, often both in Romanized form and Chinese phonetic transliteration, sometimes accompanied by a photograph. For instance, the traditional long knife, which appears in Chinese (as “長刀”) is glossed in a note which provides an explanation of the object with its Puyuma name, both in Romanized transcription ("daraw") and in a Chinese phonetic transliteration (“搭繞," i.e. "darao") (19, note 2). In fact, the notes showcase different options of negotiating between Puyuma and Chinese, as translation or by explaining non-translated terms that can themselves appear either in Romanized script or as phonetic transcriptions in Chinese characters. In contrast, the main text eschews the introduction of terms unfamiliar to a non-Puyuma reader of standard Chinese. ${ }^{10}$ Even exclamations are rendered either only in Chinese or in Puyuma with Chinese translations. In this way, counter to the more common practice of leaving an unfamiliar word in a text and glossing it in the margins or providing an appendix, Badai's text opts to bracket Puyuma words, leaving it to a reader's interest to seek out the original term and its cultural meaning. In spite of the significant presence of Puyuma text in the dialogue-heavy parts of the novel, which clearly advertises the status of the novel as an Indigenous text, it can still be read as if it were just another piece of Chinese literature. The Puyuma text, though clearly visible, need not influence or encroach upon the reading process itself, unless a reader chooses to trace and activate the information about Puyuma language and culture that the author provides in the margins.

Badai's choice of leaving standard Chinese largely isolated from and untroubled by Puyuma even elicits the series editor's criticism in his epilogue to the novel. While lauding Diguwan as an important attempt at the form of a long novel, series editor Wuhe also takes it to task for its lack of hybridity, rendering Diguwan "a Chinese (漢文) work written from a Chinese-language mindset (漢語思考)” (379). For Wuhe, an Indigenous mindset would have to infuse Chinese with Indigenous structures and energy, thus troubling standard Chinese, while also ultimately enriching it $(379-80)$. But even as Wuhe's critique resonates with theoretical celebrations of cultural hybridity as a strategy of resistance, its argumentative strategy gives new vigor and rigor to the binary of a

10 In contrast, Badai's anthropological study of Puyuma shamanism, Daramaw, written in standard Chinese, provides readers with Puyuma terms, accompanied by Chinese translations or glosses in brackets initially, then presupposes a reader's familiarity with the Puyuma terms thus introduced for the remainder of the text. 
Chinese against an Indigenous mindset, even as it advocates for linguistic mixing (although in the shape of a unidirectional impact of Puyuma on Chinese, half parasitic, half nurturing). Badai's stubborn, at times quite problematic linguistic and script mixing (or non-mixing) keeps Chinese and Puyuma apart, but also offers different modes of reading for different readers: as a novel in standard Chinese on Puyuma history, as an unofficial anthropological account, or as a sourcebook of spoken Puyuma. We can certainly critique Diguwan's carefully delimited bilingualism with its unidirectional translation from Puyuma to Chinese, since it reduces cross-cultural friction and linguistic alienation to a minimum for readers of the dominant literary language of standard Chinese. We can also read it as an experimental, yet effective way of putting into action Taiwanese cultural and script politics, precisely because it showcases the starkly uneven position of standard Chinese and Puyuma.

\section{Multiple Translations}

In marked contrast to Badai's closely policed Chinese-Puyuma bigraphism in Diguwan stands Rahic Talif's book Turbidity (Mangotaay 混濁), a work whose publication in 2006 precedes that of Badai's novel in Ryefield's Indigenous Writers' Series. From the outset, with its bilingual title in Chinese and the Amis language Pangcah, Turbidity announces itself as a hybrid work. Its pages reunite shorter pieces of various literary genres, such as poems, prose texts, and short stories, as well as featuring multiple reproductions of drawings by the author. While some of these are of village scenes, most sketches show abstract sculptures, the author's own artwork, thus folding a non-verbal, threedimensional art form into the pages of the book..$^{11}$ The occasional use of page backgrounds in different shades of grey, the use of different fonts, the inclusion of some handwritten manuscript pages, and the varied distribution of poetic text on the pages further underline the hybrid nature of the book, suggesting its status as art object that invites its reader to peruse its different facet at will rather than mandating a linear process of reading.

A similar approach characterizes Turbidity's language and script politics, as the distribution of Chinese (and thus Sinitic script) and of Romanized Pangcah differs from piece to piece. While some shorter, typically poetic texts are written entirely in standard Chinese and some few entirely in Pangcah,

11 In fact, in Rahic Talif's volume, writing is often equated with artistic and artisanal pursuits such as sculpting or rattan weaving. 
most texts show various forms of linguistic and script mixing. ${ }^{12}$ For instance, proper names and place names are usually rendered in Romanized Pangcah and capitalized. Throughout, individual Pangcah terms reoccur in the standard Chinese texts, although their use is by no means systematic, after all, the book is not conceived of as a linear structure. While most of these terms, such as "ina" ("mother,") "mama" ("father,") "kapah" ("youth") are glossed at some point in the text-it remains unclear if all the notes are by the editor, as the wording of some suggests, or if some are the author's choice-a word might have recurred several times without gloss in a linear reading of the text before the reader arrives at an explanation. ${ }^{13}$ This invites a reader to be attentive to lexical repetitions throughout Turbidity, with the result that one comes away with a small vocabulary of Pancah words even after a superficial reading of the text.

There where Turbidity presents text in Pangcah that goes beyond single terms to form expressions and sentences it is usually followed by a translation or a short explanation in standard Chinese, but Pangcah is not limited to direct discourse and can, in fact, complete a sentence begun in standard Chinese. While the volume's mixed prose texts usually follow the pattern of parallel translation, although the flexible integration of Pangcah phrases with the Chinese text makes for less rigid transitions between the two languages and scripts, the bilingual poems of the volume multiply contest a smooth translatability assumption. For instance, while the parallel arrangement of poetic text in standard Chinese and Pangcah on one page or on two opposite pages suggests that one is a translation of the other-though it remains unclear which one is the original, which one the translation-some similarly arranged poems contest this structure. For instance, the poem "做釣竿” ("Making a Fishing Rod") and "tata'ang ko hakhak no cidal" ("Glutinous Rice Galore under the Sun"), for which no Chinese title is provided, as would be expected for poems in Pangcah with no Chinese equivalent, are placed on opposite book pages, suggesting that they maintain a relationship of translations (16-17). But "Making a Fishing Rod" features Pancah terms and phrases that differ recognizably from the text of the Pangcah poem on the next page. For a reader of standard Chinese without knowledge of Pangcah it is precisely because of the Pangcah elements, rather than because of Chinese translations, that both poems can be identified as independent from each other. Thus, even though standard Chinese is still

\footnotetext{
12 In most cases, monolingual texts follow a title provided in both languages.

13 Glossed terms are printed in bold letters, but only upon their first mention on a page that contains their explanation.
} 
the dominant language throughout Turbidity, either as medium of creation or of translation, the text uses mechanisms that do not allow a reader to dispense completely with Pangcah.

Even there where translation happens between Pangcah and standard Chinese, Rahic Talif reflects critically on the possibility of a seamless movement from one language to the other. The poem "dongec" (the name of a plant used in Indigenous cooking and weaving) for instance, comes with two translations into Chinese, one designated as “字譯”, i.e. a literal translation, the other as “意譯, i.e. a translation that focuses on conveying the meaning of the original. While both Chinese texts are readable, the literal rendition, somewhat less syntactically elegant, without being grammatically incorrect, weaves a hybrid imaginary in which the dongec plant constitutes the core of Amis culture, as something the young have to learn how to plait as well as a model that can guide them, and finally as an oblique metaphor for the role of the young for the future of the community. The freer translation concretizes the analogical relationship between the dongec and the Amis youths by describing the development of personal and social maturity explicitly as a process like the complex plaiting of the dongec that is rooted in and sustains tribal culture. The presence of two different translations of one text from Pangcah into standard Chinese underlines the multi-layered complexity of textual transfer between standard Chinese and Pancah, not merely a question of choosing words in another language that carry the same meaning or writing them in a different script, but the construction of a precarious bridge, constantly teetering between the toofamiliar and the too-foreign, between two cultural spheres with their unequal, yet intertwined histories.

Two other poems, “Lekal Makor 老頭目” (“Old Headman") and "kongko 傳" ("Orature") espouse yet another strategy to highlight the complexities of translation. Here, the Chinese text of each poem, with its bilingual title, is accompanied by a version in Pangcah with Chinese words underneath each poetic line, spaced so as to show the equivalences of each single word. ${ }^{14}$ This provides a non-Pangcah reader with a sense of Pangcah's linguistic structure, without parsing grammatical structures and particles, as a full linguistic analysis would require. But whereas "Old Headman" shows many instances of differences in syntax and word order between Chinese and Pangcah, for "Orature"

14 This practice of double translation only appears in two of Rahic Talif's poems in this volume, but it accrues special significance, since the very first text of the volume, a preface by Sakuma 蕭清秀, Pangcah teacher at the local elementary school, uses the same strategy, i.e. it is written in Pangcah with word glosses in Chinese followed by a Chinese translation $(2-3)$. 
the literal parsing differs only slightly from the translated version. In fact, some parts of the Chinese text of "Orature," such as its last three lines, coincide in both versions:

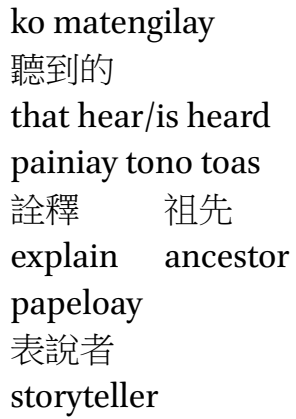

This is no longer due to a felicitous coincidence in word order and syntax of the Chinese and Pangcah versions as in the rest of "Orature"-after all the two languages belong to different language families and function quite differently. Rather, the translated version intentionally reproduces the ungrammatical structure of the parsed version, one in which the relationships between the two verbs ("to hear" and "to explain") and the two nouns ("ancestor" and "storyteller") remain ambiguous. Rather than providing a smooth, idiomatic, and grammatically correct standard Chinese translation for which the word glosses of the literal translation are only a preparation or an expendable surplus, it is precisely the occasional lack of difference between these two types of translation that signals how Pangcah intentionally interferes with standard Chinese syntax. From a different vantage point, however, apparently a complex interlingual, translational maneuver is needed in order to produce a Pangcah inflection of standard Chinese, especially for it to be perceived as an intentional intervention, rather than a consequence of inadequate Chinese literacy. In fact, "Orature" shows that the hybridization of Chinese by way of Indigenous languages that critics of Indigenous, Taiwanese, and Sinophone literatures are wont to invoke requires hard work and translational astuteness on the part of the Indigenous author.

Moments like these in the context of multiple experiments with and between Pangcah and standard Chinese in Turbidity force a reader to question the boundaries between creation and translation, as well as between original and translation. Even as Rahic Talif models some of his poems on the form of bilingual poetry editions, he effectively troubles the illusion of equality that the side-by-side placement of text in two languages suggests, but that 
usually obscures a relation of inequality - between original and translation, between different languages and their unequal status. Is standard Chinese in the parallel poems of Turbidity the host or the guest language, does it reshape the creation or translation in Pangcah or is it itself reshaped in the process? Chinese remains the dominant language throughout Turbidity. After all, Rahic Talif's work features more Chinese than Pangcah texts and Pangcah elements are normally placed within larger portions of Chinese texts, while Chinese text usually dispenses with a translation into Pangcah, whereas the instances of untranslated or unglossed Pangcah are relatively few. And yet, the multiplicity of strategies of mixing and translation between Pangcah and standard Chinese already complicates the assumption of a general, unspecific hybridity. After all, as Turbidity shows, even as both languages remain starkly unequal, the stakes of writing in standard Chinese and Pangcah are stacked anew with each literary endeavor that creates a new literary contact zone, thus opening up the extremes of assimilation or resistance to a multitude of specific linguistic interventions.

\section{Global Transcriptions}

Badai's and Rahic Talif's works find different ways of navigating the complexities of literary and linguistic marginality, as their experiments of translation, transcription, and linguistic mixing also depend strongly on each work's generic, formal, aesthetic, and political aims. Meanwhile, they tread the fine line between two different languages and scripts in a context in which the distribution of linguistic hybridity and hegemony is closely policed, both by national interests and economic realities. To assure their circulation on the Taiwanese literary scene, which also functions as one of the global distribution centers of Sinophone literature, even such hybrid Indigenous works have to rely on standard Chinese as a medium of creation and translation. But these two texts show that bilingual and bigraphic works and their politics of translation are not only determined by the interaction of a dominant (standard Chinese) and a minor (Pangcah or Puyuma) language and their respective cultural traditions.

Taiwanese Indigenous literature addresses the problem of uneven, disparate minority statuses in Taiwan, both synchronically and diachronically. For instance, Badai's Diguwan narrates a situation of tension between Japanese, the language of the colonial force, and Puyuma (and at times Bunun) as well as Taiwanese in the early decades of the twentieth century. But his novel, written for readers of standard Chinese, effectively translates this into a textual 
predominance of standard Chinese over Puyuma and Taiwanese. Even though Badai does not provide dialogue in the original Bunun and Japanese, given the topic of intertribal friction and colonial oppression in Diguwan, the novel questions the relationship between different colonized and marginalized traditions and languages as well as between colonizer and colonized cultures. Effectively, Diguwan thus paints a panorama of the complex cultural interactions in Taiwan in the past and the present, a network of hierarchical and lateral links. In fact, the work of Taiwanese Indigenous writers always points beyond its own specific bilingual or bicultural situation, as one node in the multiethnic, multilingual context of contemporary Taiwan, and, given Taiwan's multiple colonial legacies, to a global history of contact and transculturation.

The very patterns of bilingual expressions espoused and contested by the authors analyzed here already place these works in the context of global textual regimes - such as the historical novel, the anthropological text, or bilingual poetry editions. These structures shape these bilingual texts-intended to circulate beyond their Indigenous linguistic locales-before they travel further in translation. Even though Indigenous communities can claim an equal share in the hybrid cultural legacies of Taiwan and stake such a claim in increasingly vocal ways, the patterns of readership of Taiwanese Indigenous texts still remains unequal. But if non-Indigenous Taiwanese readers (or other readers of Chinese but not of Indigenous languages) often expect a readable text (in standard Chinese) that nevertheless delivers an authentic vision of Indigenous cultures, such essentializing and exoticizing visions of Indigeneity are increasingly contested in Taiwanese Indigenous writing, as Indigenous communities espouse a hybrid, bicultural, and bilingual Taiwaneseness without jettisoning their Indigenous roots.

If Taiwanese Indigenous texts put pressure on the relationship between the local (Puyuma, Amis etc.) and the national (Taiwanese), they also reframe patterns of global circulation beyond and outside of expected, trodden paths. The usual frameworks used for thinking about Taiwanese Indigenous literature in transnational terms are twofold. On the one hand, these texts are being treated as examples of Sinophone texts, as expressions (mainly) in Chinese whose minor inflection of a major language contests the monolithic essence of Chinese culture. While this has been a productive way of drawing more attention to this corpus of texts it also threatens to overemphasize the resistant potential of marginal texts in a minor key in the face of linguistic and cultural inequality and to treat the non-Chinese textual elements as an expendable extra. On the other, Taiwanese Indigenous literature has started to garner international interest beyond Taiwan or other Sinophone contexts, exemplified by criticism in non-Sinophone academia and by translations into English. 
English translations that do not only target a specialized audience often market Taiwanese Indigenous works as part of world literature, as of global importance because it brings local histories and traditions to readers of English around the world.

The translations of Taiwanese Indigenous literary works into English are inevitably driven by difficult choices. After all, as Jacques Derrida claims in Schibboleth, bilingual texts are truly untranslatable. They can be rendered into other languages, but a translation will never be able to reproduce the relationship between the two (or more) languages of the original (54-55). Bigraphic texts increment the problem of translation, since they represent not only the unequal relationship between two different languages, but the concomitant tension between two different scripts. Much like the interaction between the Romanized scripts of Indigenous languages and the Chinese writing system such a translation also consists of a movement between two different scripts, a transcription that is more than simply a change of writing system. But even as the Romanized script (shared by Indigenous writing systems and many other global languages) shows its hegemonic power vis-à-vis the Chinese script, as the dominant and indeed only script of a translated version, it also potentially erases one of the most powerful features of Taiwanese Indigenous writing: its multi-scriptural (and indeed multi-transcriptural) politics. As Taiwanese Indigenous texts circulate in English translations, the initial imbalance between the prestigious Chinese script and the Romanized transcription systems of Indigenous languages are brought into the fold of English, the language of global prestige par excellence, and their original script difference is swallowed up by the global alphabetic monopoly in which Indigenous terms barely stand out among their alphabetic frame in English. ${ }^{15}$ With a view to allowing Taiwanese Indigenous texts to travel well in English, translators often have to choose to downplay elements that make these texts particularly intriguing to a reader. For instance, John Balcolm, the translator of the first anthology of Taiwanese Indigenous literature into English, professes to have eschewed a rendition of non-grammatical or non-standard constructions of Chinese in the texts, opting for a translation into "normal American English," while maintaining the Indigenous terms used in the original text (xxii). While it might be difficult to imagine the use of a minored English to imitate the minored Chinese of the

15 Arguably, my own work, that of an academic working and publishing mainly in an AngloAmerican context who reads in standard Chinese, but can only precariously parse a couple of sentences in Pangcah also partakes of the potentially problematic global circulation of Taiwanese Indigenous literature, bringing it into the fold of western academic discourse in English, while insisting on its bilingual and bigraphic creativity. 
originals - after all, such minor uses of English are never neutral but come with their specific local, colonial, and transcultural histories - the outcome of Balcolm's translations, laudable for their elegance and for the scope of the project, seems to zoom too quickly from linguistic friction to a smooth (almost) monolingual, unmarked English. The English translation of Badai's novel Diguwan even chooses to omit the dialogues in Puyuma and Taiwanese and translates their translations into standard Chinese only, while omitting all notes, explanations, and photographs that endow Diguwan with its anthropological flavor. ${ }^{16}$

But, as Walter Mignolo points out, "If English is the hegemonic language in a transnational world, English can also be the transnational language in which positions of subalternity are rearticulated" (31). For Taiwanese Indigenous writing, such a rearticulation of marginality in English might start by paying attention to and targeting specific, strategic transcultural networks that break down the deceptive unity of the global. One such venue, in the key of a minor transnationalism (Lionnet and Shih) that effectively contests national boundaries, is the framework of the trans-Indigenous, of speaking to and resonating with the cultural expressions of Indigenous peoples around the globe. An anthology of English translations of selected works by the Taiwanese Indigenous writers Husluman Vava 霍斯陸曼·伐伐, Auvini Kadresengan 奧威尼·卡露斯, and Badai, effectively makes such a claim in its afterword, namely that these translations "make the stories accessible for a wide range of English-speaking readers, including academics fluent in English as a second language and many native peoples throughout the world who have been colonized by the British and Americans and speak fluent English as a result" (Anderson 172). From this perspective, English - much like Chinese that, for instance for Badai, can enable the communication between the different Indigenous peoples of Taiwancan provide a common medium for trans-Indigenous circulation, highlighting the "mobility and multiple interactions of Indigenous peoples, cultures, histories, and texts," "the complex, contingent asymmetry and the potential risks of unequal encounters" (Allen xiv). ${ }^{17}$

Indigenous works-even those that are written in one language only (most often the language of the colonizer) — are already involved in multiple transla-

16 Only a few parts of Rahic Talif's Turbidity have been translated into English, and notably the translator's choice has not singled out the author's textual games with bilingual poetry editions, see Russell.

17 One can nevertheless hope that future translations, maybe inspired by the bilingual and bigraphic texts of Taiwanese Indigenous writers, find new ways of dealing with the complexities at the intersections of different languages and scripts even as they mediate between and bridge different linguistic and cultural contexts. 
tional processes before their translation into another language. As such, their production and circulation has the potential to challenge cultural and linguistic boundaries and contest the definition of the local, the national, and the global. Texts such as Badai's Diguwan and Rahic Talif's Turbidity with their selective bigraphism and translational strategies, mediated by transcultural textual forms like anthropological writing or bilingual poetry editions, in fact teach us that untranslatability is not an absolute threshold. Instead, strategies of textual production and circulation between languages, cultures, and scripts are specific and unequal, even as they can be productively brought to bear on other contexts. But these texts also show us that the potential for resistance to oppressive language politics - be they local, national, regional, or globaldoes not reside in language or script mixing per se. Often global commodification and cross-cultural alliance, exoticizable hybridity and transcultural disruption are only a step apart, brokered by the author's textual choices that are themselves determined by a multiplicity of contexts, but also dependent on the strategies of reading we espouse. Even as texts can set us on a bilingual or bigraphic road, it is also up to us, as readers and critics, to play our part by engaging in ethical practices of bilanguaging and indeed biscripting.

\section{Works Cited}

Allan, Chadwick. Trans-Indigenous: Methodologies for Global Native Literary Studies. Minneapolis: University of Minnesota Press, 2012.

Anderson, John M. "Afterword." In Voices from the Mountain: Husluman Vava, Auvini Kadresengan, Badai, ed. David R. Braden. Trans. Shu-hwa Shirley Wu. Taipei: Serenity International, 2014, 172-175.

Badai 巴代. Daramaw: Beinanzu Dabaliujiu buluo de wuxi wenhua 卑南族大巴六九 部落的. 巫悓文化 (Daramaw: Shamanic Culture among the Damalagaw Puyuma). Banqiao: Yelu, 2009.

Badai 巴代. Diguan: Dabaliujiu buluo zhi dazheng nian jian 笛鸛：大巴六九部落之 大正年間 (Diguwan: Damalagaw during the Taisho Years). Taipei: Ryefield, 2007; Translated as Sorceress Diguwan by Catherine Hsiao. Taipei: Serenity International, 2013.

Badai 巴代. Matielu: Dabaliujiu buluo zhi dazheng nian jian 馬鐵路：大巴六九部落之 大正年間 (Mazizir: Damalagaw during the Taisho Years II). Banqiao: Yelu, 2010.

Balcolm, John, and Yingtsih Balcom, ed. and trans. Indigenous Writers of Taiwan: An Anthology of Stories, Essays, \& Poems. New York: Columbia UP, 2005.

Chen Li 陳黎. Daoyu Bianyuan 島嶼邊緣 (the Edge of the Island). Taipei:Jiuge, 2003. Chen Li 陳黎. Qing/man 輕/慢 (Light/Slow). Taipei: Eryu, 2007. 
Derrida, Jacques. De la grammatologie. Paris: Minuit, 1967.

Derrida, Jacques. Schibboleth: Pour Paul Celan. Paris: Galilée, 1986.

Huang Hsinya. "Sinophone Indigenous Literature of Taiwan: History and Tradition." In Sinophone Studies: A Critical Reader, ed. Shu-mei Shih, Chien-hsin Tsai, and Brian Bernards. New York: Columbia UP, 2013, 242-254.

Lionnet, Françoise and Shu-mei Shih, "Introduction: Thinking through the Minor, Transnationally." In Minor Transnationalism, ed. Françoise Lionnet and Shu-mei Shih. Durham: Duke UP, 2005, 1-23.

Liu, James J.Y. Chinese Theories of Literature. Chicago and London: The University of Chicago Press, 1975.

Lü Huizhen 呂慧珍. Shuxie buluojiyi:Jiu ling niandai Taiwanyuanzhumin xiaoshuoyanjiu 書寫部落記憶: 九零年代台灣原住民小說研究 (Writing Memories of the Village: Research on Taiwanese Indigenous Novels of the 199os). Taipei: Luotuo, 2003.

Mignolo, Walter. Local Histories/Global Designs. 2nd ed. Princeton, NJ: Princeton UP, 2012.

Rahic Talif 拉黑子. 達立夫. Mangotaay/Hunchuo 混濁 (Turbidity). Taipei: Ryefield, 2006 (a few select pieces from Turbidity have been translated by Terence C. Russell in Taiwan Literature: English Translation Series 22 (2008): 111-123).

Sommer, Doris. "Introduction." In Bilingual Games: Some Literary Investigations, ed. Doris Sommer. New York: Palgrave, 2003, 1-18.

Sun Dachuan 孫大川. "Yuanzhumin wenhua lishi yu xinling shijie moxie: Shi lun yuanzhumin wenxue de keneng” 原住民文化歷史與心靈世界摹寫：試論原住民文學的 可能 (“Depicting The Cultural History and Inner World of Taiwan's Aborigines: An Attempt at Discussing the Possibility of Indigenous Literature"). In Taiwan yuanzhumin hanyu wenxue xuanji: pinglunjuan I 台灣原住民漢語文學選集：評論卷 I (Indigenous Chinese-language literature of Taiwan: Criticism I), ed. Sun Dachuan. Taipei: Ink, 2003, 17-47.

Zeitoun, Elizabeth and Ching-Hua Yu. "The Formosan Language Archive: Linguistic Analysis and Language Processing." Computational Linguistics and Chinese Language Processing 10: 2 (2005), 167-200. 